\title{
Effects on Mood of Acute Phenylalanine/ Tyrosine Depletion in Healthy Women
}

\author{
M. Leyton, Ph.D., S. N. Young, Ph.D., R. O. Pihl, Ph.D., S. Etezadi, C. Lauze, R.N.,
} P. Blier, M.D., Ph.D., G. B. Baker, Ph.D., and C. Benkelfat, M.D.

Catecholamines have been implicated in the etiology and pathophysiology of mood and anxiety disorders. In the present study, we investigated the effects of experimentally reducing catecholamine neurotransmission by means of acute phenylalanine/tyrosine depletion (APTD). Healthy female volunteers ingested: (1) a nutritionally balanced amino acid (AA) mixture $(\mathrm{n}=14)$; (2) a mixture deficient in the serotonin precursor, tryptophan ( $\mathrm{n}=15)$; or (3) one deficient in the catecholamine precursors, phenylalanine and tyrosine $(\mathrm{n}=12)$. Mood was measured at three times: at baseline and both immediately before and after an aversive psychological challenge (public speaking and mental arithmetic) conducted 5 hours after AA mixture ingestion. Acute tryptophan depletion (ATD) lowered mood and energy and increased irritability scores. These effects were statistically significant only after the psychological challenge. The effect of APTD on mood was similar to that of ATD. APTD did not attenuate the anxiety caused by the psychological challenge. These findings suggest that, in healthy women, reduced serotonin and/or catecholamine neurotransmission increases vulnerability to lowered mood, especially following exposure to aversive psychological

events. [Neuropsychopharmacology 22:52-63,

2000] (C) 1999 American College of

Neuropsychopharmacology. Published by Elsevier Science Inc.
KEY WORDS: Norepinephrine; Dopamine; Serotonin; Tryptophan; Depression; Anxiety; Stress; Cardiovascular activity

Brain catecholamines are thought to be involved in the regulation of mood (Bunney and Davis 1965; Depue and Iocono 1989: Schildkraut 1965), anxiety (Charney et al. 1984), appetitive motivation (Blackburn et al. 1992; Koob 1996: Stewart 1995), reward (Wise 1996), and attention to novel environmental stimuli (Redmond 1987). In some patients exhibiting disturbances in these behaviors, cerebrospinal fluid (CSF) concentrations of cat-

From the Department of Psychiatry (ML, SNY, SE, CL, PB, CB), the Department of Psychology (ROP), and the School of Dietetics and Human Nutrition (SNY), McGill University, Montréal, Québec, Canada; and Department of Psychiatry (GBB), University of Alberta, Edmonton, Alberta, Canada.

Address correspondence to: Simon N. Young, Ph.D., Department of Psychiatry, McGill University, 1033 Pine Avenue West, Montréal, Québec, H3A 1A1, Canada.

Received August 26, 1998; revised June 29, 1999; accepted July 16, 1999. echolamine metabolites are altered (Depue and Iocono 1989; Pitchot et al. 1992; Redmond et al. 1986; Schildkraut 1978; Siever 1987). Both dopamine and noradrenaline neurons are activated following exposure to environmental stressors (Abercrombie and Zigmond 1995). Activation of noradrenaline neurons may increase anxiety (Redmond 1987), whereas moderate activation of midbrain dopamine neurons seems to increase psychomotor activity and responses to emotionally relevant stimuli (Le Moal 1995). In comparison, reductions in noradrenaline (Schatzberg and Schildkraut 1995) and dopamine (Willner 1995) neurotransmission may be involved in the etiology of depression, although the evidence for dopamine is weaker.

The suggestion that low levels of catecholamines may predispose humans to lowered mood and psychomotor retardation, but decreased anxiety, has led to experimental studies of this hypothesis. Decreased dopaminergic function can be elicited experimentally using low doses of apomorphine, which are thought to act as a presynap- 
tic agonist. However, problems with apomorphine include concern about its specificity for the presynaptic, rather than postsynaptic receptor, and side effects (Lal 1988). Another approach is to inhibit tyrosine hydroxylase with $\alpha$-methyl-p-tyrosine (AMPT). Repeated administration of AMPT produces primarily fatigue and sedation (Engelman et al. 1968; Sjoerdsma et al. 1965), although also mild decreases in self-reported "happiness" and "calmness," which are reversed by L-dopa (McCann et al. 1993; McCann et al. 1995). However, AMPT can also produce both acute dystonic reactions (McCann et al. 1990) and crystalluria (Brogden et al. 1981). In comparison to the effects of reducing catecholamine synthesis, administration of the catecholamine amino acid (AA) precursor, tyrosine, attenuates moodlowering (Banderet and Lieberman 1989) and cognitive deficits (Deijen and Orlebeke 1994; Neri et al. 1995) associated with stressful environmental challenges.

Recently, a new method has been developed for testing the effects of reduced catecholamine synthesis, acute depletion of the catecholamine precursors, phenylalanine and tyrosine (Moja et al. 1996; Sheehan et al. 1996). This method is analogous to the acute tryptophan depletion (ATD) method which transiently decreases brain serotonin synthesis (Moja et al. 1984; Nishizawa et al. 1997; Young et al. 1985) and release (Bel and Artigas 1996; Heslop et al. 1991; Stancampiano et al. 1997). ATD has been used to investigate the role of serotonin in the regulation of mood (Ellenbogen et al. 1996; Young et al. 1985), impulsive behaviors (Lemarquand et al. 1999), aggressive responding (Cleare and Bond, 1995; Pihl et al. 1995), and the mechanism of antidepressant action (Bremner et al. 1997; Delgado et al. 1990).

In the acute phenylalanine/tyrosine depletion (APTD) method, participants ingest a mixture of essential AAs that is deficient in the catecholamine precursors, phenylalanine and tyrosine. This induces protein synthesis, which diminishes the body's stores of phenylalanine and tyrosine, because they are incorporated into protein. Because tyrosine hydroxylase, the rate-limiting enzyme in catecholamine synthesis, normally is not fully saturated with tyrosine (Carlsson and Lindqvist 1978), the reduced availability of tyrosine will likely reduce catecholamine synthesis. The magnitude of the decline of catecholamine synthesis following APTD might vary with regional and individual differences in rates of cell firing, catecholamine stores, and the affinity state of tyrosine hydroxylase. Dopaminergic projections to the nucleus accumbens and to the prefrontal and cingulate cortices may be especially dependent upon tyrosine availability (During et al. 1988; Tam et al. 1990), and this dependency seems to be greatest when firing rates, and, therefore, precursor utilization, are high (Milner and Wurtman 1986; Tam and Roth 1997).

In rats, APTD has been reported to decrease caudate concentrations of tyrosine and the dopamine (DA) me- tabolites homovanillic acid (HVA) and 3,4-dihydroxyphenylacetic acid (DOPAC), although not DA itself (Biggio et al. 1976). More recently, APTD was reported to reduce the rate of tyrosine hydroxylation, as measured by decreased DOPA accumulation following administration of the aromatic L-amino acid decarboxylase inhibitor, m-hydroxybenzylhydrazine (NSD-1015) (Fernstrom and Fernstrom 1995). In vervet monkeys, APTD decreased CSF concentrations of both HVA and the norepinephrine (NE) metabolite, 3-methoxy4-hydroxyphenylethylene glycol (MHPG) and did so to a similar extent that ATD reduces 5-hydroxyindoleacetic acid (5-HIAA) (Palmour et al. 1998). Two recent studies indicate that APTD reduces plasma concentrations of tyrosine and phenylalanine in humans (Moja et al. 1996; Sheehan et al. 1996).

The behavioral and physiological effects of APTD remain largely unexplored. Palmour et al. (1998) observed that APTD decreased voluntary alcohol consumption in alcohol-preferring monkeys, a behavioral change suggestive of decreased DA-mediated appetitive motivation or reward. Moja et al. (1996) reported that APTD significantly decreased blood pressure, possibly reflecting lowered catecholamine function. In contrast, Sheehan et al. (1996) reported that APTD failed to decrease evening plasma concentrations of melatonin, suggesting that the treatment had no effect on peripheral noradrenergic function.

In the present study, we measured the effects of APTD and ATD on mood and anxiety in healthy women. We have found previously that ATD lowers brain serotonin synthesis more in women than in men (Nishizawa et al. 1997). ATD also lowered mood in healthy women but not healthy men (Ellenbogen et al. 1996), possibly because of the greater biochemical effect, but also possibly because of the greater susceptibility of women to lowered mood. For both these reasons, we studied healthy women in the present study. Lowering an amino acid in the amino acid depletion technique is attributable to protein synthesis, so if ATD lowers tryptophan more in women than in men, APTD would be expected to lower tyrosine more in women than in men. To assess whether APTD reduces anxiety, we evaluated subjects both before and after a mildly threatening psychological challenge, public speaking. We hypothesized that APTD would lower mood and energy and blunt the anxiety response to the psychological challenge.

\section{SUBJECTS AND PROCEDURES}

\section{Subjects}

Healthy female participants, aged 19 to 39, were recruited through local newspaper advertisements. Women were studied because we found previously that ATD 
lowers mood in healthy women, but not in healthy men (Ellenbogen et al. 1996). All potential participants were screened initially during a telephone interview. They were then evaluated further (ML) with the Structured Clinical Interview for DSM-III-R (SCID-NP; Spitzer 1987). Exclusion criteria included a personal or firstdegree relative history of axis I psychiatric disorders, a Beck Depression Inventory (BDI; Beck et al. 1961) score above 10, a positive urine drug screen (Triage Panel for Drugs of Abuse), and a positive pregnancy test. None had significant medical diseases, as determined by clinical judgment from a physical examination (PB) and laboratory tests. All were tested during their follicular phase (Range: days 1-12).

\section{Procedure}

The study was a double-blind, between-groups design. Group assignment to AA condition was made randomly in blocks of six. The day before testing, all subjects ate a low protein diet provided by the investigators and fasted from midnight before the experimental day (see Benkelfat et al. 1994). On the test day, subjects arrived at the laboratory at 8:30 A.M. and had blood samples drawn for the measurement of baseline plasma concentrations of AAs. They then ingested one of three AA mixtures: (1) an 86-g nutritionally balanced (B) control AA mixture; (2) a similar mixture deficient in tryptophan (Trp-); or (3) one deficient in phenylalanine and tyrosine (Phe/Tyr-). The composition of the AA mixtures is based on the 100-g AA mixture used by us in men (Young et al. 1985) and subsequently adapted for the lower body weight of women (Ellenbogen et al. 1996). The drinks were prepared within a few minutes of oral administration by mixing the powdered AAs with either: (1) $150 \mathrm{ml}$ water, $45 \mathrm{ml}$ chocolate syrup, and $0.6 \mathrm{~g}$ of sodium cyclamate; or (2) $180 \mathrm{ml}$ of orange juice plus sodium cyclamate, according to the preference of the subjects. Because of the unpleasant taste of methionine, cysteine, and arginine, these AAs were encapsulated and administered separately.

Following ingestion of the AA mixtures, the women remained awake in a room with affectively neutral videos and reading material available to them. One hour after ingestion, they completed the vocabulary and block design tests from the Weschler intelligence scale (WAIS). Five hours after ingestion, they underwent a mild threatening psychological challenge, a slightly modified version of the Trier Social Stress Test (Kirschbaum et al. 1993). The 5-hour interval was chosen on the basis of monkey data showing that CSF catecholamine metabolite levels are lowered at this time (Palmour et al. 1998). In addition, after ATD in humans, plasma tryptophan reaches it lowest level after about 5 hours (Young et al. 1985). Because the mechanism for the decline in tryptophan and tyrosine is the same [i.e., incorporation of the relevant amino acid into protein, thereby depleting its level in blood and tissues (Moja et al. 1991)], tyrosine might be expected to reach its lowest level after 5 hours, as does tryptophan.

The modified Trier Social Stress Test consisted of two parts, a 10-min Anticipation Period and a 10-min Test Period. During the Anticipation Period, subjects were asked to prepare a speech suitable for applying for a job. They were told that their speech would be recorded for later analysis, and a videocamera with microphone was visible. They were then given $10 \mathrm{~min}$ to prepare and take notes but were not allowed to use them during their speech. During the Test Period, subjects presented their 5-min speech followed by $5 \mathrm{~min}$ of arithmetic problems. If a subject stopped her speech before her time ( $5 \mathrm{~min}$ ), she was told "You still have some time left. Please continue!" If the subject stopped a second time before the $5 \mathrm{~min}$ were up, 20 seconds of silence were followed by the arithmetic problem solving (in the present study, this occurred only once). The arithmetic problems consisted of repeatedly adding the digits of a three-digit number to form successive new numbers (e.g., 654; $6+5+4=15 ; 15+654=669 ; 6+$ $6+9=21 ; 21+669=690$, etc). Answers were to be given aloud. If the subject made a mistake, she was asked to begin from the first number.

Blood pressure and heart rate were monitored throughout the stress test. Blood pressure was measured using a Model Acutorr 3 Sat from Datascope. The pressure cuff was attached to the nondominant upper arm and inflated at 5-min intervals.

Mood scales were administered three times. At baseline, before ingesting the AA mixture, subjects completed the BDI, the bipolar Profile of Mood States (POMS; Lorr et al. 1982; McNair et al. 1988), and a visual analog mood scale (VAMS; Bond and Lader 1974). Five hours after ingestion of the mixture, the same scales were administered again. Immediately following the psychological challenge, the POMS and VAMS were completed for a third time. The POMS is composed of six bipolar scales: elated-depressed; composed-anxious; energetic-tired; agreeable-hostile; confident-unsure; and clear headed-confused. The VAMS has $10-\mathrm{cm}$ horizontal lines, each representing a mood state, on which the subject was instructed to place a mark that best described her current state. The POMS is highly sensitive to nonclinical changes in mood states. As in our previous studies, the primary dependent measure was the POMS. Thus, the primary measure of lowering of mood was the elated-depressed scale of the POMS, the primary measure of lowered energy was the energetic-tired scale of the POMS; whereas, the primary measures of the blunting of the anxiety response were the composed-anxious scale of the POMS and the cardiac responses to the stress test. The main measure on the VAMS was the depression scale. The other 
VAMS measures were included to see if any other aspect of mood changed and to maintain consistency with previous work on ATD (Ellenbogen et al. 1996), so that comparisons could be made across studies.

At the end of each test day, before returning home, all subjects ate a high-protein snack and ingested a 1-g L-tryptophan tablet. Phenylalanine and tyrosine were not given in tablet form, because they are present in protein at much higher levels than tryptophan. The tryptophan preparation used in Canada has not been associated with any cases of eosinophilia myalgia syndrome (Wilkins 1990).

Total and free (nonalbumin bound) plasma tryptophan concentrations were measured as described previously (Benkelfat et al. 1994). Plasma concentrations of phenylalanine and tyrosine were analyzed using highperformance liquid chromatography (HPLC) with fluorescence detection. Ice-cold methanol $(150 \mu \mathrm{l})$ was added to plasma $(50 \mu \mathrm{l})$ on ice. Following homogenization and centrifugation, 5- $\mu$ l of the supernatant was reacted with o-phthaldialdehyde in an alkaline medium in the presence of 2-mercaptoethanol (Sloley et al. 1992). The reaction mixture was injected into a Waters Alliance 2690 XE sample handling system. Separation was accomplished using a gradient system on a Waters Spherisorb ODS2 column $\left(\mathrm{C}_{18}, 5 \mu \mathrm{m}, 4.6 \times 250 \mathrm{~mm}\right)$ connected to a Waters $\mu$ Bondapak $C_{18}$ precolumn. The detector was set at $254 \mathrm{~nm}$ (excitation wavelength) and $455 \mathrm{~nm}$ (emission wavelength). Plasma concentrations of the other large neutral amino acids (LNAAs) were analyzed by the gas chromatographic procedure of Wong et al. (1990). This procedure involves sequential derivatization with isobutyl chloroformate and pentafluorophenol followed by analysis on a gas chromatograph equipped with a fused silica capillary column and an electron-capture detector.

No measurements were made of catecholamines or their metabolites in plasma or urine, because these measures would reflect primarily effects on catecholamine synthesis in the periphery, which would not necessarily be of the same magnitude as those in the brain. Thus, tyrosine availability in the brain, but not in the periphery, is influenced by the levels of the other large neutral amino acids that inhibit the transport of tyrosine in the brain (Oldendorf and Szabo 1976).

\section{Data Analyses}

POMS scores were converted to population normalized $t$ scores. A change of 10 points corresponds to one standard deviation (SD) in the general population.

Demographic characteristics were analyzed with one-way between groups analyses of variance (ANOVAs). Behavioral, cardiovascular, and blood data were analyzed by two-way between-within groups ANOVAs (group $\times$ time). Both absolute scores and change
$(\Delta)$ scores were analyzed. When there were significant group differences on the test day at baseline, the baseline scores were used as covariates in analyses of covariance (ANCOVAs) of the $\Delta$ scores. Planned comparisons were made with Student's $t$-tests; the behavioral data were corrected for planned multiple comparisons. Fisher's Exact Tests (one-tailed) were used to compare the proportion of subjects in each group that vomited and dropped out of the study.

\section{Ethics}

The study was carried out in accordance with the Declaration of Helsinki and was approved by the Research Ethics Board of the Royal Victoria Hospital, McGill University. All subjects gave informed written consent. Subjects were given $\$ 70$ (CAN) compensation for loss of time related to their participation.

\section{RESULTS}

\section{Baseline Measures and Demographic Characteristics}

The demographic and baseline characteristics of the subjects are displayed in Table 1 . The three groups did not differ significantly on age, body mass index (BMI), cardiovascular activity, Beck Depression Inventory (BDI) scores, and the Weschler intelligence scale (WAIS) vocabulary and block scores.

On the test day, before ingestion of the AA mixture, some baseline differences were noted. Compared to the control Group B, Group Phe/Tyr- reported lower POMS Energy-Tired scores $(p<.02)$ and higher VAMS Depression $(p<.03)$ and BDI scores $(p<.002)$. Compared to Group Trp-, both Group B $(p<.03)$ and Group Phe/Tyr- $(p<.02)$ reported higher baseline VAMS Excited scores; Group Phe/Tyr- reported higher baseline BDI scores $(p<.0008)$ (Table 2). Unless otherwise indicated, all subsequent analyses use $\Delta$ scores. When baseline differences were apparent, the pretreatment score was used as a covariate in ANCOVAs of the $\Delta$ scores.

\section{Effects of Trp- and Phe/Tyr- on Plasma Amino Acids}

Plasma concentrations of free and total tryptophan decreased significantly following Trp- (free tryptophan: $p<.00001$; Total Tryptophan: $p<.0000001)$ and increased significantly following both the balanced mixture (free tryptophan: $p<.00001$; total tryptophan: $p<$ .00001 ) and Phe/Tyr- (free tryptophan: $p<.00001$; total tryptophan: $p<.00001)$. There were no significant differences at baseline (free tryptophan: $p>.25$; total tryptophan: $p>$.70) (Table 3).

As reflected by significant treatment $\times$ time interactions, the three AA mixtures also had significantly different effects on plasma concentrations of phenylala- 
nine $\left(\mathrm{F}_{(2,34)}=20.53, p<.000002\right)$ and tyrosine $\left(\mathrm{F}_{(2,34)}=\right.$ $24.53, p<.0000004)$. Following Phe/Tyr-, plasma concentrations of both phenylalanine $(p<.007)$ and tyrosine $(p<.04)$ decreased significantly; whereas, they increased following ingestion of the balanced (phenylalanine: $p<.0002$; tyrosine: $p<.0000003$ ) and tryptophandeficient mixtures (phenylalanine: $p<.000002$; tyrosine: $p<.0000002)$. There were no significant differences at baseline (phenylalanine: $p>.80$; tyrosine: $p>.60$ ) (Table 3 ).

The ratio of tyrosine to large neutral amino acids (LNAA: tryptophan, tyrosine, phenylalanine, leucine, isoleucine, valine) was calculated using the free tryptophan concentration. All three mixtures significantly decreased the tyrosine/LNAA ratio (B: $p<.03$; Trp-: $p<.003$; Phe/Tyr-: $p<.0000001)$. However, as reflected by a significant treatment $x$ time interaction, these effects were markedly more pronounced following Phe/ Tyr- than the other two mixtures $\left(\mathrm{F}_{(2,33)}=8.40, p<\right.$ .002). A similar treatment $\times$ time interaction was seen with the phenylalanine/LNAA ratio $\left(\mathrm{F}_{(2,33)}=14.88, p<\right.$ .00003). In comparison, Phe/Tyr- did not significantly change the tryptophan/LNAA ratio $(p>.10)$ (Table 3$)$.

\section{Effects of Trp- and Phe/Tyr- on Mood}

Trp- vs. Balanced AA Mixture. Five hours after administration of the AA mixtures, there were few significant group differences. Compared to Group B, Group Trp- displayed greater decreases in POMS ConfidentUnsure scores $(p=.05)$, greater decreases in VAMS Lively scores $(p<.007)$, and blunted increases in VAMS Restless scores $(p<.003)$. On the other hand, following the psychological challenge, Trp- resulted in significant mood lowering on all six POMS scales: Elation-Depression $(p<.03)$, Composed-Anxious $(p<.04)$, EnergeticTired $(p<.01)$, Agreeable-Hostile $(p<.05)$, ConfidentUnsure $(p<.01)$, and Clearheaded-Confused $(p<$ .0008) (Figure 1). ANCOVAs indicated that the mood lowering was unrelated to pretreatment BDI scores. VAMS scores also suggested greater mood lowering in Group Trp- following the psychological challenge. Compared to Group B, Group Trp- reported significantly greater negative changes on the VAMS Happy $(p<.03)$, Irritated $(p<.04)$, Lively $(p<.000007)$, and Clearheaded scales $(p=.05)$ (Table 2).

Phe/Tyr-vs. Balanced AA Mixture. Before the psychological challenge, Phe/Tyr- led to reduced increases in VAMS Restlessness $(p<.005)$ and larger decreases on the VAMS Lively scale $(p<.02)$, as compared to controls (Table 3). After the psychological challenge, the larger decreases on the VAMS Lively scale were again apparent $(p<.02)$, and subjects reported mood lowering on the POMS Elated-Depressed scale $(p<.001)$ (Figure 1). An ANCOVA with pretreatment BDI scores as the covariate did not change the effect on mood, accounting for less than 0.03 of the variance.

Phe/Tyr- vs. Trp-. When groups Trp- and Phe/Tyrwere compared, Trp- led to significantly greater negative changes on the POMS Agreeable-Hostile scale $(p<$ $.03)$, although only after the psychological challenge. Phe/Tyr- led to significantly greater negative changes in VAMS Bored scores, both before $(p<.004)$ and after the psychological challenge $(p<.05)$.

Correlations Between Scores Before and After the Psychological Challenge. Although neither Trp- nor Phe/ Tyr- AA mixtures induced extensive mood lowering before the psychological challenge, these change scores were significantly correlated with the larger changes reported following the psychological challenge $(r=0.46$ to 0.84$)$.

\section{Effects of Trp- and Phe/Tyr- on Heart Rate and Blood Pressure}

Heart Rate. In all three groups, heart rate changed significantly during the psychological challenge $\left(\mathrm{F}_{(8,288)}=\right.$ $42.11, p<.0000001)$. Compared to baseline, heart rate increased significantly during anticipation and preparation of the challenge, reached a peak during the speech and mathematical tasks, and then returned to baseline (data not shown). Neither Trp- nor Phe/Tyrhad a significant effect on heart rate, as reflected by the absence of a main effect of Group $\left(\mathrm{F}_{(2,36)}=2.75, p<.08\right)$ or a Group $\times$ Time interaction $\left(\mathrm{F}_{(16,288)}=0.49, p>.90\right)$.

Systolic Blood Pressure. In all three groups, systolic blood pressure changed significantly as a result of the psychological challenge $\left(\mathrm{F}_{(8,248)}=13.26, p<.0000001\right)$. Collapsed over groups, systolic blood pressure was significantly higher throughout the psychological challenge than at any other point, except for the second baseline $(p<.0002)$. There was neither a main effect of Group $\left(\mathrm{F}_{(2,31)}=0.04, p>.95\right)$ nor a significant Group $\times$ Time interaction $\left(\mathrm{F}_{(16,248)}=1.54, p<.09\right)$ (data not shown).

Diastolic Blood Pressure. In all three groups, diastolic blood pressure changed significantly during the psychological challenge $\left(\mathrm{F}_{(8,248)}=8.37, p<.0000001\right)$. Collapsed over groups, diastolic blood pressure was significantly higher during the psychological challenge than at any other time point except for the second baseline $(p<.05)$. There was not a main effect of Group $\left(\mathrm{F}_{(2,31)}=\right.$ $0.35, p>.70)$ but there was a significant Group $\times$ Time interaction $(\mathrm{F}(16,248)=2.13, p<.008)$. In Group B, diastolic blood pressure decreased during the anticipation phase, increased during the speech and math tasks, and then returned to baseline (lowest value immediately before beginning speech; highest value at the end of the math task; $p<.0002$, data not shown). In compar- 
Table 1. Demographic and Baseline Characteristics

\begin{tabular}{lccc}
\hline & \multicolumn{3}{c}{ Amino Acid Mixture } \\
\cline { 2 - 4 } Variable & $\begin{array}{c}\text { Balanced } \\
(\boldsymbol{n}=\mathbf{1 4})\end{array}$ & $\begin{array}{c}\text { Tryptophan Deficient } \\
(\boldsymbol{n}=\mathbf{1 5})\end{array}$ & $\begin{array}{c}\text { Phenylalanine/Tyrosine-Deficient } \\
(\boldsymbol{n}=\mathbf{1 2})\end{array}$ \\
\hline Age (years) & $26.6 \pm 4.9$ & $27.9 \pm 6.4$ & $26.2 \pm 6.5$ \\
Body mass index $(\mathrm{kg} / \mathrm{m} 2)$ & $23.1 \pm 3.0$ & $22.3 \pm 3.3$ & $20.6 \pm 2.8$ \\
Heart rate (beats/min) at medical exam & $74.0 \pm 8.0$ & $72.0 \pm 5.6$ & $75.9 \pm 11.9$ \\
Systolic blood pressure at medical exam & $109.0 \pm 8.2$ & $109.1 \pm 11.4$ & $103.3 \pm 12.7$ \\
Diastolic blood pressure at medical exam & $67.1 \pm 7.9$ & $67.1 \pm 7.4$ & $66.7 \pm 6.2$ \\
Beck depression inventory at SCID interview & $2.6 \pm 2.3$ & $2.4 \pm 2.6$ & $3.6 \pm 3.2$ \\
WAIS vocabulary & $49.5 \pm 8.9$ & $51.5 \pm 10.5$ & $45.2 \pm 9.6$ \\
WAIS block & $34.5 \pm 11.3^{*}$ & $30.8 \pm 13.3$ & $35.6 \pm 12.8$ \\
Menstrual cycle day at test & $7.5 \pm 3.1$ & $7.4 \pm 3.4$ & $7.8 \pm 3.5$ \\
\hline
\end{tabular}

${ }^{*} n=13$.

Values are given as mean \pm SD.

ison, neither Group Trp- nor Phe/Tyr- displayed decreases during the anticipation phase.

\section{Adverse Effects}

Three subjects withdrew from the study. All had ingested the Phe/Tyr- mixture (Fisher's Exact Test, Phe/Tyr- vs. Balanced AA, $p=.12$; Phe/Tyr-vs. Trp-, $p=.11$ ). The primary reported reason for withdrawing was nausea, and all three regurgitated some of the AA mixture.

The subjects who withdrew from the study did not differ significantly from those who remained, although there was a trend for them to have a lower body mass index (BMI; $\mathrm{kg} / \mathrm{m}^{2}$ ) (study completers vs. withdrawing subjects: $22.1 \pm 3.1$ vs. $18.5 \pm 0.6$; planned Comparison, $\left.\mathrm{F}_{(1,40)}=3.83, p=.06\right)$.

Two women administered the Phe/Tyr- mixture had a vagal response following the second blood draw. Both women recovered within 2 minutes, and no further adverse events were found. One of the women withdrew from the study, the other completed it.

Including the three subjects who withdrew, a total of 11 women vomited (25\%); six had been administered the Trp- mixture (40\%), five the Phe/Tyr- mixture (33\%), none the balanced mixture (Fisher's Exact Test, Trp- vs. Balanced AA, $p<.02$; Phe/Tyr- vs. Balanced, $p<.03$; Phe/Tyr- vs. Trp-, $p>.25)$. Only subjects who completed the study were included in the remaining data analyses. The reported effects are not significantly changed by excluding the women who vomited (e.g., POMS Elated-Depressed $\Delta$ scores following the psychological challenge: including subjects who vomited: Trp-: $-4.7 \pm 6.2$, Phe/Tyr-: $-6.0 \pm 6.2$; excluding subjects who vomited: Trp-: $-4.9 \pm 7.4$, Phe/Tyr-: $-6.2 \pm 7.5$ ).

\section{DISCUSSION}

The most important finding in this study is that APTD and ATD had similar effects on mood. Both treatments elicited a lowering of mood, relative to a control amino acid mixture, that became statistically significant after the psychological challenge. It is not clear to what extent the difference in the effects seen before and after the challenge is dependent upon the stress of the challenge itself, or merely on the progressive development of lowered mood over time after amino acid depletion. These observations suggest that both low catecholamine and low serotonin neurotransmission might increase risk for depressed states, particularly following exposure to stressors, at least in healthy women, who were the subjects of this study. There was no evidence for an attenuation of the anxiety response to a mild aversive challenge attributable to APTD.

The change attributable to ATD in POMS depression scale scores before the psychological challenge was similar to that in our previous study in healthy women (Ellenbogen et al. 1996). However, although this effect was statistically significant in our previous two-group study, in the present study, with three groups, the difference was not statistically significant once corrections for multiple comparisons were made.

Although there was a significant lowering of mood after APTD on the POMS depression scale, there was no significant effect on the VAMS depression scale. However, the VAMS depression scale scores were around 1 out of a possible 10, suggesting that the VAMS depression scale is only sensitive to larger changes in mood, unlike the POMS, which is known to be sensitive to small changes of mood. The VAMS happy scale scores did not decline after APTD, suggesting that, as with the VAMS depression scale scores, VAMS happy scale scores measure only large changes in mood. Alternatively, although there is evidence that the precise dimensions measured by the POMS are bipolar (Lorr et al. 1982), the dimensions measured by the VAMS may not be bipolar.

Some subjects experienced nausea and vomiting, and it is possible that this influenced the mood scales. 
Table 2. Changes on the VAMS Following the Ingestion of a Balanced (B), a Tryptophan-Deficient (Trp-), or a Phenylalanine/Tyrosine-Deficient (Phe/Tyr-) Amino Acid Mixture

\begin{tabular}{|c|c|c|c|c|c|c|}
\hline $\begin{array}{l}\text { VAMS } \\
\text { Item }\end{array}$ & Group & $\begin{array}{c}\text { Before } \\
\text { AA } \\
\text { Mixture }\end{array}$ & $\begin{array}{c}5 \text { hrs after } \\
\text { AA } \\
\text { Mixture }\end{array}$ & $\begin{array}{c}\text { After } \\
\text { Stressor }\end{array}$ & $\begin{array}{c}\text { Change Score } \\
\text { before vs. } \\
5 \text { hrs after } \\
\text { AA Mixture }\end{array}$ & $\begin{array}{l}\text { Change score } \\
\text { before vs. } \\
\text { after Stressor }\end{array}$ \\
\hline Happy & $\begin{array}{l}\text { B } \\
\text { Trp- } \\
\text { Phe/Tyr- }\end{array}$ & $\begin{array}{l}6.7 \pm 1.7 \\
6.2 \pm 1.5 \\
6.5 \pm 1.7\end{array}$ & $\begin{array}{l}6.1 \pm 1.7 \\
4.9 \pm 2.5 \\
5.7 \pm 2.1\end{array}$ & $\begin{array}{l}5.9 \pm 2.0^{d} \\
4.4 \pm 1.7^{A, c} \\
5.2 \pm 2.2\end{array}$ & $\begin{array}{l}-0.5 \pm 1.6 \\
-1.2 \pm 2.4 \\
-0.8 \pm 1.7\end{array}$ & $\begin{array}{l}-0.7 \pm 2.0^{d} \\
-1.8 \pm 2.0^{c} \\
-1.4 \pm 1.9\end{array}$ \\
\hline Bored & $\begin{array}{l}\text { B } \\
\text { Trp- } \\
\text { Phe/Tyr- }\end{array}$ & $\begin{array}{l}1.6 \pm 1.2 \\
2.7 \pm 2.4 \\
2.7 \pm 2.8\end{array}$ & $\begin{array}{l}4.6 \pm 2.7^{A} \\
4.3 \pm 2.8^{e} \\
6.8 \pm 2.0^{A, d}\end{array}$ & $\begin{array}{l}3.5 \pm 2.2 \\
3.6 \pm 2.4 \\
5.5 \pm 2.1^{A}\end{array}$ & $\begin{array}{l}3.1 \pm 2.4 \\
1.6 \pm 3.2^{E} \\
4.2 \pm 2.7^{D}\end{array}$ & $\begin{array}{l}2.0 \pm 2.1 \\
0.9 \pm 3.5^{e} \\
2.8 \pm 2.6^{d}\end{array}$ \\
\hline Anxiety & $\begin{array}{l}\text { B } \\
\text { Trp- } \\
\text { Phe/Tyr- }\end{array}$ & $\begin{array}{l}1.4 \pm 1.9 \\
1.9 \pm 1.6 \\
3.1 \pm 2.8\end{array}$ & $\begin{array}{l}1.4 \pm 1.6 \\
1.5 \pm 1.4 \\
2.9 \pm 2.6\end{array}$ & $\begin{array}{l}2.3 \pm 2.8 \\
1.7 \pm 2.3^{E} \\
4.1 \pm 2.7^{D}\end{array}$ & $\begin{array}{r}0.0 \pm 1.2 \\
-0.5 \pm 1.0 \\
-0.2 \pm 3.7\end{array}$ & $\begin{array}{r}0.9 \pm 1.9 \\
-0.2 \pm 1.6 \\
1.0 \pm 3.3\end{array}$ \\
\hline Satisfied & $\begin{array}{l}\text { B } \\
\text { Trp- } \\
\text { Phe/Tyr- }\end{array}$ & $\begin{array}{l}6.5 \pm 2.4 \\
5.9 \pm 2.0 \\
5.7 \pm 2.2\end{array}$ & $\begin{array}{l}5.6 \pm 2.4 \\
4.7 \pm 2.8 \\
4.8 \pm 2.0\end{array}$ & $\begin{array}{l}5.6 \pm 2.2 \\
4.0 \pm 2.2 \\
5.0 \pm 1.6\end{array}$ & $\begin{array}{l}-0.9 \pm 2.1 \\
-1.2 \pm 2.1 \\
-0.8 \pm 3.3\end{array}$ & $\begin{array}{l}-1.0 \pm 3.3 \\
-1.9 \pm 2.0 \\
-0.7 \pm 3.3\end{array}$ \\
\hline Excited & $\begin{array}{l}\text { B } \\
\text { Trp- } \\
\text { Phe/Tyr- }\end{array}$ & $\begin{array}{l}5.0 \pm 2.3^{d} \\
3.1 \pm 2.2^{e} \\
5.1 \pm 2.7^{d}\end{array}$ & $\begin{array}{l}3.8 \pm 2.7 \\
2.2 \pm 2.1 \\
3.1 \pm 2.5\end{array}$ & $\begin{array}{l}3.6 \pm 62.6^{d} \\
1.7 \pm 1.9^{c, E} \\
4.0 \pm 2.6^{D}\end{array}$ & $\begin{array}{l}-1.2 \pm 2.5 \\
-0.9 \pm 1.6 \\
-1.9 \pm 2.7\end{array}$ & $\begin{array}{l}-1.4 \pm 2.0 \\
-1.3 \pm 2.0 \\
-1.2 \pm 2.7\end{array}$ \\
\hline Depressed & $\begin{array}{l}\text { B } \\
\text { Trp- } \\
\text { Phe/Tyr- }\end{array}$ & $\begin{array}{l}0.4 \pm 0.5^{e} \\
1.0 \pm 0.9 \\
1.3 \pm 1.6^{c}\end{array}$ & $\begin{array}{l}0.4 \pm 0.4^{E} \\
0.8 \pm 0.8^{e} \\
1.7 \pm 2.7^{C, d}\end{array}$ & $\begin{array}{l}0.6 \pm 0.6^{E} \\
0.8 \pm 0.6^{E} \\
2.0 \pm 2.8^{C, D}\end{array}$ & $\begin{array}{r}0.1 \pm 0.4 \\
-0.3 \pm 0.8 \\
0.4 \pm 1.6\end{array}$ & $\begin{array}{r}0.2 \pm 0.7 \\
-0.2 \pm 0.6^{E} \\
0.6 \pm 1.8^{D}\end{array}$ \\
\hline Interest & $\begin{array}{l}\text { B } \\
\text { Trp- } \\
\text { Phe/Tyr- }\end{array}$ & $\begin{array}{l}7.2 \pm 2.3 \\
6.6 \pm 1.9 \\
7.2 \pm 1.6\end{array}$ & $\begin{array}{l}5.7 \pm 2.5 \\
5.4 \pm 3.1 \\
5.0 \pm 2.4^{a}\end{array}$ & $\begin{array}{l}5.6 \pm 2.5^{D} \\
3.6 \pm 2.5^{A, C, E} \\
5.8 \pm 2.6^{D}\end{array}$ & $\begin{array}{l}-1.5 \pm 2.8 \\
-1.2 \pm 1.8 \\
-2.2 \pm 2.0\end{array}$ & $\begin{array}{l}-1.6 \pm 2.9^{d} \\
-3.0 \pm 1.7^{c, e} \\
-1.4 \pm 2.1^{d}\end{array}$ \\
\hline Anger & $\begin{array}{l}\text { B } \\
\text { Trp- } \\
\text { Phe/Tyr- }\end{array}$ & $\begin{array}{l}0.2 \pm 0.3 \\
0.8 \pm 0.9 \\
0.5 \pm 0.5\end{array}$ & $\begin{array}{l}0.3 \pm 0.4 \\
0.6 \pm 0.5 \\
0.4 \pm 0.4\end{array}$ & $\begin{array}{l}0.3 \pm 0.4 \\
1.2 \pm 2.4 \\
0.5 \pm 0.5\end{array}$ & $\begin{array}{r}0.1 \pm 0.2 \\
-0.2 \pm 0.6 \\
-0.0 \pm 0.4\end{array}$ & $\begin{array}{l}0.1 \pm 0.3 \\
0.4 \pm 2.7 \\
0.0 \pm 0.3\end{array}$ \\
\hline Elated & $\begin{array}{l}\text { B } \\
\text { Trp- } \\
\text { Phe/Tyr- }\end{array}$ & $\begin{array}{l}3.7 \pm 2.8 \\
2.8 \pm 1.7 \\
3.0 \pm 2.6\end{array}$ & $\begin{array}{l}2.9 \pm 2.6 \\
2.3 \pm 1.8 \\
1.7 \pm 1.7\end{array}$ & $\begin{array}{l}3.0 \pm 2.7 \\
1.9 \pm 1.6 \\
2.4 \pm 2.6\end{array}$ & $\begin{array}{l}-0.8 \pm 2.7 \\
-0.5 \pm 2.1 \\
-1.3 \pm 2.6\end{array}$ & $\begin{array}{l}-0.7 \pm 3.1 \\
-0.9 \pm 1.4 \\
-0.6 \pm 1.4\end{array}$ \\
\hline Restless & $\begin{array}{l}\text { B } \\
\text { Trp- } \\
\text { Phe/Tyr- }\end{array}$ & $\begin{array}{l}2.2 \pm 2.5 \\
1.2 \pm 1.5 \\
2.9 \pm 1.7\end{array}$ & $\begin{array}{l}5.5 \pm 3.1^{A, D} \\
2.6 \pm 3.0^{C} \\
4.2 \pm 2.8\end{array}$ & $\begin{array}{l}4.4 \pm 3.4^{a} \\
2.7 \pm 2.8 \\
4.5 \pm 2.7\end{array}$ & $\begin{array}{l}3.3 \pm 2.7^{D, E} \\
1.3 \pm 3.6^{C} \\
1.4 \pm 2.2^{C}\end{array}$ & $\begin{array}{l}2.2 \pm 2.7 \\
1.5 \pm 3.4 \\
1.6 \pm 2.4\end{array}$ \\
\hline Irritated & $\begin{array}{l}\text { B } \\
\text { Trp- } \\
\text { Phe/Tyr- }\end{array}$ & $\begin{array}{l}1.1 \pm 1.9 \\
1.0 \pm 1.0 \\
0.9 \pm 1.0\end{array}$ & $\begin{array}{l}0.8 \pm 0.9 \\
1.1 \pm 1.2 \\
1.0 \pm 1.2\end{array}$ & $\begin{array}{l}1.1 \pm 1.5 \\
2.0 \pm 2.9 \\
1.1 \pm 1.6\end{array}$ & $\begin{array}{r}-0.3 \pm 1.8 \\
0.2 \pm 1.5 \\
0.1 \pm 1.7\end{array}$ & $\begin{array}{c}-0.1 \pm 2.4^{d} \\
1.1 \pm 3.1^{c} \\
0.2 \pm 1.9\end{array}$ \\
\hline Lively & $\begin{array}{l}\text { B } \\
\text { Trp- } \\
\text { Phe/Tyr- }\end{array}$ & $\begin{array}{l}4.8 \pm 2.9 \\
5.0 \pm 2.5 \\
5.4 \pm 2.5\end{array}$ & $\begin{array}{l}4.4 \pm 2.4 \\
3.2 \pm 2.7^{a} \\
3.6 \pm 2.2\end{array}$ & $\begin{array}{l}4.4 \pm 2.8^{D} \\
2.2 \pm 1.9^{A, C} \\
3.5 \pm 2.8^{a}\end{array}$ & $\begin{array}{l}-0.4 \pm 1.9^{D, e} \\
-1.8 \pm 2.4^{C} \\
-1.8 \pm 1.9^{c}\end{array}$ & $\begin{array}{l}-0.5 \pm 2.2^{D, e} \\
-2.8 \pm 2.4^{C} \\
-1.8 \pm 2.6^{c}\end{array}$ \\
\hline Clearheaded & $\begin{array}{l}\text { B } \\
\text { Trp- } \\
\text { Phe/Tyr- }\end{array}$ & $\begin{array}{l}7.7 \pm 1.8 \\
7.3 \pm 2.4 \\
6.8 \pm 2.3\end{array}$ & $\begin{array}{l}6.4 \pm 2.6 \\
6.2 \pm 2.4 \\
5.8 \pm 2.4\end{array}$ & $\begin{array}{l}6.6 \pm 2.6 \\
4.8 \pm 2.7^{A} \\
5.2 \pm 2.8\end{array}$ & $\begin{array}{l}-1.3 \pm 3.0 \\
-1.1 \pm 1.7 \\
-1.0 \pm 2.4\end{array}$ & $\begin{array}{l}-1.1 \pm 3.0^{d} \\
-2.5 \pm 3.1^{c} \\
-1.6 \pm 2.8\end{array}$ \\
\hline
\end{tabular}

Values are given as mean \pm SD. For the B group $n=14$, for the Trp- group $n=15$, and for the Phe/Tyr- group $n=12$. VAMS indicates Visual Analogue Mood Scale (0-10). A positive change in score represents an increase in that item's intensity.

${ }^{a} p \leqslant .05,{ }^{A} p \leqslant .01$, different from before treatment, corrected for multiple planned comparisons $(0.05 / 18=0.0028 ; 0.01 / 18=0.00056)$.

${ }^{b} p \leqslant .05,{ }^{B} p \leqslant .01$, different from 5 hours after treatment, corrected for multiple planned comparisons $(0.05 / 18=0.0028 ; 0.01 / 18=0.00056)$.

${ }^{c} p \leqslant .05,{ }^{c} p \leqslant .01$, different from B, corrected for multiple planned comparisons $(0.05 / 6=0.0083 ; 0.01 / 6=0.0017)$.

${ }^{d} p \leqslant .05,{ }^{D} p \leqslant .01$, different from Trp-, corrected for multiple planned comparisons $(0.05 / 6=0.0083 ; 0.01 / 6=0.0017)$.

$e_{p} \leqslant .05, E_{p} \leqslant .01$, different from Phe/Tyr-, corrected for multiple planned comparisons $(0.05 / 6=0.0083 ; 0.01 / 6=0.0017)$. 
Table 3. Changes to Plasma Concentrations of Amino Acids Following Ingestion of a Balanced (B), a Tryptophan-Deficient (Trp-), or a Phenylalanine/Tyrosine-Deficient (Phe/Tyr-) Amino Acid Mixture

\begin{tabular}{|c|c|c|c|c|}
\hline Amino Acid & Group & $\begin{array}{l}\text { Before AA } \\
\text { Mixture }\end{array}$ & $\begin{array}{c}5 \mathrm{~h} \text { after } \\
\text { AA Mixture }\end{array}$ & $\begin{array}{l}\text { Percent } \\
\text { Change }\end{array}$ \\
\hline \multirow[t]{3}{*}{ Free plasma tryptophan } & $\mathrm{B}(n=13)$ & $8.4 \pm 2.8$ & $17.6 \pm 2.6$ & 109.5 \\
\hline & Trp- $(n=13)$ & $7.9 \pm 1.8$ & $1.3 \pm 0.6$ & -83.6 \\
\hline & Phe/Tyr- $(n=10)$ & $7.2 \pm 0.6$ & $17.2 \pm 5.7$ & 138.9 \\
\hline \multirow[t]{3}{*}{ Total plasma tryptophan } & $\mathrm{B}(n=13)$ & $50.4 \pm 4.8$ & $100.5 \pm 14.9$ & 99.4 \\
\hline & $\operatorname{Trp}-(n=13)$ & $52.6 \pm 10.1$ & $6.9 \pm 3.6$ & -84.9 \\
\hline & Phe/Tyr- $(n=11)$ & $50.8 \pm 7.5$ & $104.6 \pm 39.8$ & 105.9 \\
\hline \multirow[t]{3}{*}{ Plasma phenylalanine } & $\mathrm{B}(n=13)$ & $63.2 \pm 10.4$ & $129.2 \pm 37.5$ & 104.4 \\
\hline & $\operatorname{Trp}-(n=13)$ & $60.6 \pm 11.8$ & $151.4 \pm 87.9$ & 149.8 \\
\hline & Phe/Tyr- $(n=11)$ & $63.7 \pm 9.6$ & $15.0 \pm 7.9$ & -76.5 \\
\hline \multirow[t]{3}{*}{ Plasma tyrosine } & $\mathrm{B}(n=13)$ & $69.5 \pm 22.8$ & $165.7 \pm 55.5$ & 138.4 \\
\hline & $\operatorname{Trp}-(n=13)$ & $74.7 \pm 14.8$ & $176.8 \pm 72.9$ & 136.7 \\
\hline & Phe/Tyr- $(n=11)$ & $68.0 \pm 14.9$ & $32.2 \pm 9.8$ & -52.6 \\
\hline \multirow{3}{*}{ Plasma valine } & $\mathrm{B}(n=13)$ & $172.5 \pm 55.6$ & $613.8 \pm 138.8$ & 255.8 \\
\hline & Trp- $(n=13)$ & $174.9 \pm 50.0$ & $644.3 \pm 247.3$ & 268.4 \\
\hline & Phe/Tyr- $(n=11)$ & $184.4 \pm 57.3$ & $652.2 \pm 186.2$ & 253.7 \\
\hline \multirow[t]{3}{*}{ Plasma leucine } & $\mathrm{B}(n=13)$ & $120.6 \pm 29.6$ & $498.6 \pm 171.5$ & 313.4 \\
\hline & $\operatorname{Trp}-(n=13)$ & $112.8 \pm 29.3$ & $447.3 \pm 190.2$ & 296.5 \\
\hline & Phe/Tyr- $(n=11)$ & $111.8 \pm 35.8$ & $458.1 \pm 226.8$ & 309.7 \\
\hline \multirow[t]{3}{*}{ Plasma iso-leucine } & $\mathrm{B}(n=13)$ & $53.6 \pm 29.6$ & $223.3 \pm 171.5$ & 316.6 \\
\hline & Trp- $(n=13)$ & $52.0 \pm 29.3$ & $203.2 \pm 190.2$ & 290.8 \\
\hline & Phe/Tyr- $(n=11)$ & $50.7 \pm 35.8$ & $189.6 \pm 226.8$ & 274.0 \\
\hline \multirow[t]{3}{*}{ Phenylalanine/LNAAs } & $\mathrm{B}(n=13)$ & $0.13 \pm 0.02$ & $0.079 \pm 0.02$ & -39.2 \\
\hline & Trp- $(n=13)$ & $0.13 \pm 0.03$ & $0.094 \pm 0.04$ & -27.7 \\
\hline & Phe/Tyr- $(n=10)$ & $0.14 \pm 0.03$ & $0.016 \pm 0.02$ & -88.6 \\
\hline \multirow[t]{3}{*}{ Tyrosine/LNAAs } & $\mathrm{B}(n=13)$ & $0.14 \pm 0.03$ & $0.11 \pm 0.05$ & -21.4 \\
\hline & Trp- $(n=13)$ & $0.16 \pm 0.03$ & $0.11 \pm 0.04$ & -31.2 \\
\hline & Phe/Tyr- $(n=10)$ & $0.15 \pm 0.05$ & $0.031 \pm 0.02$ & -79.3 \\
\hline \multirow{3}{*}{$\begin{array}{l}\text { Tryptophan/LNAAs } \\
\text { free tryptophan }\end{array}$} & $\mathrm{B}(n=13)$ & $0.017 \pm 0.003$ & $0.011 \pm 0.02$ & -35.3 \\
\hline & Trp- $(n=13)$ & $0.017 \pm 0.004$ & $0.00088 \pm 0.0006$ & -94.8 \\
\hline & Phe-Tyr- $(n=10)$ & $0.015 \pm 0.004$ & $0.014 \pm 0.004$ & -6.7 \\
\hline \multirow{3}{*}{$\begin{array}{l}\text { Tryptophan/LNAAs } \\
\text { total tryptophan }\end{array}$} & $\mathrm{B}(n=13)$ & $0.098 \pm 0.02$ & $0.060 \pm 0.01$ & -38.8 \\
\hline & Trp- $(n=13)$ & $0.10 \pm 0.02$ & $0.0049 \pm 0.004$ & -95.1 \\
\hline & Phe-Tyr- $(n=11)$ & $0.098 \pm 0.02$ & $0.076 \pm 0.03$ & -22.4 \\
\hline
\end{tabular}

Values are given as mean $\pm \mathrm{SD}$ in $\mu \mathrm{mol} / 1$

However, the results did not change when subjects who vomited were omitted. Also, in a previous study on ATD, we used an instructional manipulation in which subjects were either supplied or not supplied with information designed to account for any possible peripheral sensations that might be related to depressive affect. This manipulation had no effect on the moodlowering effect of ATD (Smith et al. 1987). Thus, sensations of nausea are unlikely to have had an appreciable effect on the mood measures.

The effects of APTD were similar to those reported to occur in response to other treatments used to decrease catecholamine neurotransmission in humans. For example, in healthy volunteers, AMPT has been reported to induce sedation, lower mood, and reduce calmness (McCann et al. 1993; McCann et al. 1995). In our study, APTD also lowered mood, energy, and calm- ness, but only the mood-lowering effect was statistically significant. The different results might reflect differences in the degree to which catecholamine synthesis was lowered, the cumulative effect of giving AMPT over a much longer time period, or nonspecific effects of AMPT. Interestingly, tyrosine loading does not produce elevations in baseline mood, but it does attenuate mood-lowering effects of environmental challenges (Banderet and Lieberman 1989). This may reflect greater utilization and depletion of precursor stores in DA cells when firing rates are high (Tam and Roth 1997).

The overlap between the effects of ATD and APTD raises the possibility that the observed mood lowering might be caused by nonspecific effects of altered AA availability or AA imbalance. However, a recent report suggests that acute depletion of another essential AA, 


\section{Five Hours Post AA Mixture}

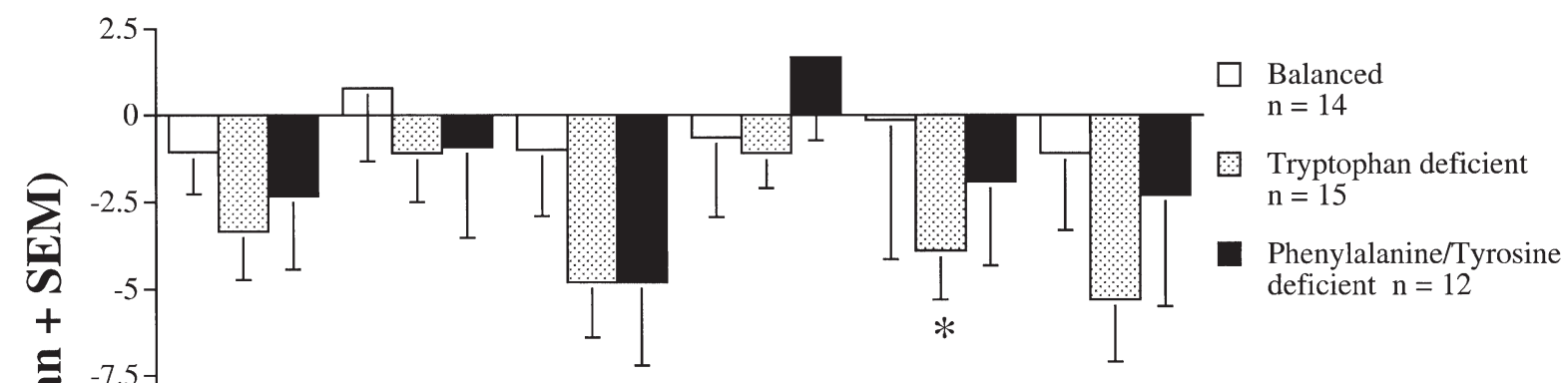

Post Psychological Challenge

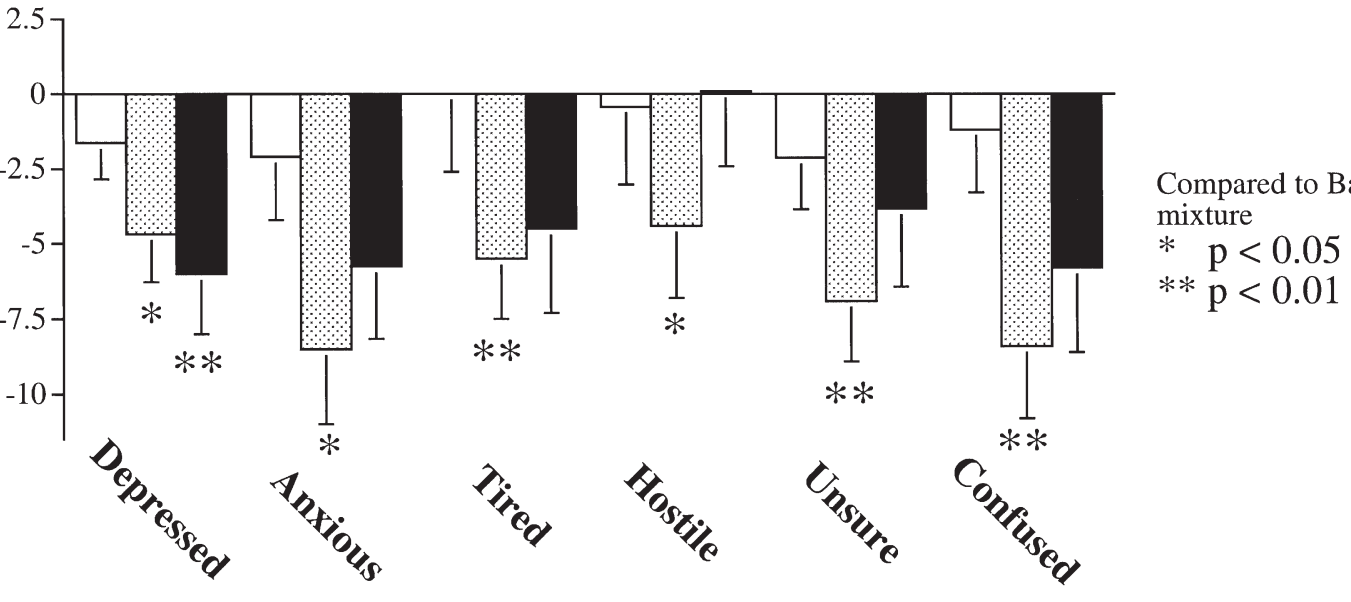

Figure 1. Changes since morning baseline in POMS Elated-Depressed mood scores induced by ingestion of the Balanced (B), Tryptophan-deficient (Trp-), or Phenylalanine/Tyrosine-deficient (Phe/Tyr-) amino acid mixtures. The plotted scores are the mean $\pm \mathrm{SE}$ of normalized T scores. A negative change in score represents a lowering in $\operatorname{mood}{ }^{*} p<.05,{ }^{* *} p<.01$.

lysine, does not affect mood in subjects who respond to ATD (Klaassen et al. 1997). Also, in the present study, differences between the effects of ATD and APTD were apparent. Only ATD significantly increased feelings of irritability, confusion and fatigue, whereas only APTD increased feelings of boredom.

There is no direct evidence that APTD decreases catecholamine neurotransmission. This noted, in the present study, APTD decreased the phenylalanine and tyrosine to LNAA ratios by 80 to $90 \%$, a reduction that would be expected to reduce transport of the catecholamine precursors into brain. The control treatment and the ATD mixture lowered the tyrosine to LNAA ratio by 21 and 31\%, respectively. Thus, the control treatment is a relatively conservative one. However, changes in the ratio of 20 to $30 \%$ would be unlikely to influence catecholamine synthesis to any appreciable extent. Changes of this magnitude are within the range of the ratio of tyrosine to LNAA that can be expected because of diurnal changes and normal variations in protein intake (Fernstrom et al. 1979).

In animals, tyrosine-deficient diets have been re- ported to decrease DOPA accumulation (Fernstrom and Fernstrom 1995) and concentrations of catecholamine metabolites (Biggio et al. 1976; Fernstrom and Fernstrom 1995) but not 5-HIAA (Palmour et al. 1998). In comparison, tyrosine loading significantly increases both DOPA accumulation and tissue concentrations of DA (Tam et al. 1990). Notably, in humans, tyrosine supplements have the opposite effect of APTD and attenuate mood-lowering responses to environmental challenges (Banderet and Lieberman 1989).

APTD has certain advantages over other methods designed to lower catecholamine neurotransmission. For example, AMPT requires multiple daily treatments, the marked sedation may mask other effects, and it has been reported to induce both crystalluria (Brogden et al. 1981) and acute dystonic reactions (McCann et al. 1990). The effects of autoreceptor agonists and postsynaptic receptor antagonists are rapid (e.g., Przedborski et al. 1995), but most are nonspecific (Broderick 1997; Closse et al. 1984; Moroni et al. 1983; Yocca 1990) and, perhaps because of regional differences in presynaptic autoreceptors and postsynaptic feedback, do not induce consistent changes 
to synthesis, cell firing, or transmitter release (Cubeddu et al. 1990; Hjorth et al. 1983; Wolf et al. 1986).

There are several disadvantages of the APTD method. First, as with AMPT, it should decrease the synthesis of both dopamine and noradrenaline, and, thus, lacks the specificity of ATD, which should affect only serotonin among the major neurotransmitters. Results from studies using other techniques must be used to infer which effects of APTD are attributable to dopamine and which are attributable to noradrenaline. Second, unlike AMPT, APTD may decrease the synthesis of the trace amines phenylethylamine and tyramine in brain. However, unlike ATD, which may lower the levels of other potentially psychoactive tryptophan metabolites, such as melatonin, quinolinic acid, and kynurenic acid, there are no other obvious metabolites of phenylalanine and tyrosine, other than trace amines, that might affect brain function. Third, as mentioned previously, APTD, as ATD, may have nonspecific effects related to amino acid imbalance. Fourth, there is no direct evidence that APTD lowers the rate of catecholamine synthesis, let alone catecholamine function, in humans. For ATD, there is evidence for a lowering of serotonin synthesis in human CNS from both PET (Nishizawa et al. 1997) and CSF (Carpenter et al. 1998) studies. However, there is no positron emission tomography (PET) method for studying the metabolic flux through tyrosine hydroxylase, so measurement of CSF catecholamines or their metabolites is the only feasible method. Meanwhile, the evidence that lowered plasma tyrosine can, under some circumstances, decrease brain catecholamines must be inferred from animals studies and the behavioral effects in humans.

In conclusion, the present study: (1) indicates that APTD decreases tyrosine to LNAA ratios by $80 \%$; (2) replicates our earlier finding that ATD can transiently lower mood in healthy women; (3) indicates that APTD can also transiently lower mood; (4) suggests that APTD does not reduce anxiety responses in healthy women; and (5) indicates that effects of both ATD and APTD are greater following exposure to a psychological challenge. This last finding might suggest that lowered monoamine synthesis decreases monoamine availability for use during periods of elevated demand; the result might be disturbed responses to psychological stressors and increased vulnerability to negative mood states. In some people, low monoamine synthesis might be a trait that increases the risk for mood disorders following exposure to stressful life events (e.g., Kendler et al. 1995; Trestman et al. 1991).

\section{ACKNOWLEDGMENTS}

This work was supported by grants from the Medical Research Council (MRC) of Canada to S.N.Y. (MT-7811) and C.B.
(MT-12502). C.B is the recipient of a Senior Chercheur-Boursier Award from the Fonds de la Recherche en Santé du Québec. P.B. is a recipient of a MRC Scientist Award. M.L. is the recipient of a Young Investigator's Award from NARSAD. The authors are grateful to Ms Franceen Lenoff and Mrs. Gail Rauw for expert technical assistance.

\section{REFERENCES}

Abercrombie ED, Zigmond MJ (1995): Modification of central catecholaminergic systems by stress and injury: Functional significance and clinical implications. In Bloom FE, Kupfer DJ (eds), Psychopharmacology: The Fourth Generation of Progress. New York, Raven Press, pp 355-361

Banderet LE, Lieberman HR (1989): Treatment with tyrosine, a neurotransmitter precursor, reduces environmental stress in humans. Brain Res Bull 22:759-762

Beck AT, Ward CH, Mendelson M, Mock JE, Erbaugh JK (1961): An inventory for measuring depression. Arch Gen Psychiat 4:561-571

Bel N, Artigas F (1996): Reduction of serotonergic function in rat brain by tryptophan depletion: Effects in control and fluvoxamine-treated rats. J Neurochem 67:669-676

Benkelfat C, Ellenbogen MA, Dean P, Palmour RM, Young SN (1994): Mood-lowering effect of tryptophan depletion: Enhanced susceptibility in young men at genetic risk for major affective disorders. Arch Gen Psychiat 51:687-697

Biggio G, Porceddu ML, Gessa GL (1976): Decrease of homovanillic, dihydroxyphenylacetic acid and cyclic-adenosine-3',5'-monophosphate content in the rat caudate nucleus induced by the acute administration of an amino acid mixture lacking tyrosine and phenylalanine. J Neurochem 26:1253-1255

Blackburn JR, Pfaus JG, Phillips AG (1992): Dopamine functions in appetitive and defensive behaviors. Prog Neurobiol 39:247-279

Bond A, Lader M (1974): The use of analog scales in rating subjective feelings. Br J Med Psychol 47:211-218

Bremner JD, Innis RB, Salomon RM, Staib LH, Ng CK, Miller HL, Bronen RA, Krystal JH, Duncan J, Rich D, Price LH, Malison R, Dey H, Soufer R, Charney DS (1997): Positron emission tomography measurement of cerebral metabolic correlates of tryptophan depletion-induced depressive relapse. Arch Gen Psychiat 54:364-374

Broderick PA (1997): Alprazolam, diazepam, yohimbine, clonidine: In vivo CA1 hippocampal norepinephrine and serotonin release profiles under chloral hydrate anesthesia. Prog Neuropsychopharmacol Biol Psychiat 21:1117-1140

Brogden RN, Heel RC, Speight TM, Avery GS (1981): $\alpha$-Methyl- $p$-tyrosine: A review of its pharmacology and clinical use. Drugs 21:81-89

Bunney WE, Davis JM (1965): Norepinephrine in depressive reactions. Arch Gen Psychiat 13:483-494

Carlsson A, Lindqvist M (1978): Dependence of 5HT and catecholamine synthesis on concentrations of precursor amino acids in rat brain. Naunyn Schmiedebergs Arch Pharmacol 303:157-164 
Carpenter LL, Anderson GM, Pelton GH, Gudin JA, Kirwin PDS, Price LH, Heninger GR, McDougle CJ (1998): Tryptophan depletion during continuous CSF sampling in healthy human subjects. Neuropsychopharmacology 19:26-35

Charney DS, Heninger GR, Breier A (1984): Noradrenergic function in panic anxiety: Effects of yohimbine in healthy subjects and patients with agoraphobia and panic disorder. Arch Gen Psychiat 41:751-763

Cleare AJ, Bond AJ (1995): The effect of tryptophan depletion and enhancement on subjective and behavioral aggression in normal male subjects. Psychopharmacology 118:72-81

Closse A, Frick W, Dravid A, Bolliger G, Hauser D, Sauter A, Tobler HJ (1984): Classification of drugs according to receptor binding profiles. Naunyn Schmiedebergs Arch Pharmacol 327:95-101

Cubeddu LX, Hoffmann IS, Talmaciu RK (1990): Is the release of dopamine from medial prefrontal cortex modulated by presynaptic receptors? Comparison with nigrostriatal and mesolimbic terminals. Ann NY Acad Sci 604:452-461

Deijen JB, Orlebeke JF (1994): Effect of tyrosine on cognitive function and blood pressure under stress. Brain Res Bull 33:319-323

Delgado PL, Charney DS, Price LH, Aghajanian GK, Landis H, Heninger GR (1990): Serotonin function and the mechanism of antidepressant action: Reversal of antidepressant-induced remission by rapid depletion of plasma tryptophan. Arch Gen Psychiat 47:411-418

Depue RA, Iocono WG (1989): Behavioral aspects of affective disorders. Ann Rev Psychol 40:457-492

During MJ, Acworth IN, Wurtman RJ (1988): Effects of systemic L-tyrosine on dopamine release from rat corpus striatum and nucleus accumbens. Brain Res 452:378-380

Ellenbogen MA, Young SN, Dean P, Palmour RM, Benkelfat C (1996): Mood response to acute tryptophan depletion in healthy volunteers: Sex differences and temporal stability. Neuropsychopharmacology 15:465-474

Engelman K, Horwitz D, Jéquier E, Sjoerdsma A (1968): Biochemical and pharmacologic effects of $\alpha$-methyltyrosine in man. J Clin Invest 47:577-591

Fernstrom JD, Wurtman RJ, Hammarstrom-Wiklund B, Rand WM, Munro HN, Davidson CS (1979): Diurnal variations in plasma concentrations of tryptophan, tyrosine, and other neutral amino acids: Effect of dietary protein intake. Am J Clin Nutr 32:1912-1922

Fernstrom MH, Fernstrom JD (1995): Acute tyrosine depletion reduces tyrosine hydroxylation rate in rat central nervous system. Life Sci 57:PL97-PL102

Heslop K, Portas CM, Curzon G (1991): Effect of altered tryptophan availability on tissue and extracellular serotonin in the rat cortex. In Rollema H, Westerink BHC, Drijfhout WJ (eds), Monitoring Molecules in Neuroscience: Proceedings of the 5th International Conference of In Vivo Methods. pp 259-261

Hjorth S, Carlsson A, Clark D, Svensson K, Wikstrom H, Sanchez D, Lindberg P, Hacksell U, Arvidsson LE, Johansson A (1983): Central dopamine receptor agonist and antagonist actions of the enantiomers of 3-PPP. Psychopharmacology 81:89-99

Kendler KS, Kessler RC, Walters EE, Maclean C, Neale MC, Heath AC, Eaves LJ (1995): Stressful life events, genetic liability, and onset of an episode of major depression in women. Am J Psychiat 152:833-842

Kirschbaum C, Pirke KM, Hellhammer DH (1993): The "Trier Social Stress Test": A tool for investigating psychobiological stress responses in a laboratory setting. Neuropsychobiology 28:76-81

Klaassen T, Riedel WJ, Deutz NEP, van Praag HM (1997): Specificity of the tryptophan depletion method. J Psychopharmacol 11:A33

Koob GF (1996): Hedonic valence, dopamine and motivation. Mol Psychiat 1:186-189

Lal S (1988): Apomorphine in the evaluation of dopaminergic function in man. Prog Neuropsychopharmacol Biol Psychiat 12:117-164

Le Moal M (1995): Mesocortical dopaminergic neurons: Functional and regulatory roles. In Bloom FE, Kupfer DJ (eds), Psychopharmacology: The Fourth Generation of Progress. New York, Raven Press, pp 283-294

Lemarquand D, Benkelfat C, Pihl RO, Palmour RM, Young SN (1999): Tryptophan depletion-induced behavioral disinhibition in nonalcoholic young men with multigenerational family histories of paternal alcoholism. Am J Psychiat in press

Lorr M, McNair DM, Fisher S (1982): Evidence for bipolar mood states. J Pers Assess 46:432-436

McCann UD, Penetar DM, Belenky G (1990): Acute dystonic reaction in normal humans caused by catecholamine depletion. Clin Neuropharmacol 13:565-568

McCann UD, Penetar DM, Shaham Y, Thorne DR, Sing HC, Thomas ML, Gillin JC, Belenky G (1993): Effects of catecholamine depletion on alertness and mood in rested and sleep-deprived normal volunteers. Neuropsychopharmacology 8:345-356

McCann UD, Thorne D, Hall M, Popp K, Avery W, Sing H, Thomas M, Belenky G (1995): The effects of L-dihydroxyphenylalanine on alertness and mood in alpha-methylpara-tyrosine-treated healthy humans: Further evidence for the role of catecholamines in arousal and anxiety. Neuropsychopharmacology 13:41-52

McNair DM, Lorr M, Droppleman LF (1988): Manual for the Profile of Mood States. San Diego, Educational and Industrial Testing Service

Milner JD, Wurtman RJ (1986): Catecholamine synthesis: Physiological coupling to precursor supply. Biochem Pharmacol 35:875-881

Moja EA, Antinoro E, Cesa-Bianchi M, Gessa GL (1984): Increases in stage 4 sleep after ingestion of a tryptophanfree diet in humans. Pharmacol Res Commun 16:909-914

Moja EA, Restani P, Corsini E, Stacchezzini MC, Assereto R, Galli CL (1991): Cycloheximide blocks the fall of plasma and tissue tryptophan levels after tryptophan-free amino acid mixtures. Life Sci 49:1121-1128

Moja EA, Lucini V, Benedetti F, Lucca A (1996): Decrease in plasma phenylalanine and tyrosine after phenylalaninetyrosine free amino acid solutions in man. Life Sci 58:2389-2395

Moroni F, Tanganelli S, Antonelli T, Carla V, Bianchi C, Beani L (1983): Modulation of cortical acetylcholine and gamma-aminobutyric acid release in freely moving guinea pigs: Effects of clonidine and other adrenergic drugs. J Pharmacol Exp Ther 227:435-440 
Neri DF, Wiegmann D, Stanny RR, Shappell SA, McCardie A, McKay DL (1995): The effects of tyrosine on cognitive performance during extended wakefulness. Aviat Space Environ Med 66:313-319

Nishizawa S, Benkelfat C, Young SN, Leyton M, Mzengeza S, de Montigny C, Blier P, Diksic M (1997): Differences between males and females in rates of serotonin synthesis in human brain. Proc Natl Acad Sci USA 94:5308-5313

Oldendorf WH, Szabo J (1976): Amino acid assignment to one of three blood-brain barrier amino acid carriers. Am J Physiol 230:94-98

Palmour RM, Ervin FR, Baker GB, Young SN (1998): An amino acid mixture deficient in phenylalanine and tyrosine reduces cerebrospinal fluid catecholamine metabolites and alcohol consumption in vervet monkeys. Psychopharmacology 136:1-7

Pihl RO, Young SN, Harden P, Plotnick S, Chamberlain B, Ervin FR (1995): Acute effect of altered tryptophan levels and alcohol on aggression in normal human males. Psychopharmacology 119:353-360

Pitchot W, Ansseau M, Gonzalez Moreno A, Hansenne M, von Frenckell R (1992): Dopaminergic function in panic disorder: Comparison with a major and minor depression. Biol Psychiat 32:1004-1011

Przedborski S, Levivier M, Raftopoulos C, Naini AB, Hildebrand J (1995): Peripheral and central pharmacokinetics of apomorphine and its effect on dopamine metabolism in humans. Movement Disord 10:28-36

Redmond DE, Katz MM, Maas JW, Swann A, Casper R, Davis JM (1986): Cerebrospinal fluid amine metabolites: Relationships with behavioral measurements in depressed, manic, and healthy control subjects. Arch Gen Psychiat 43:938-947

Redmond DE (1987): Studies of the nucleus locus coeruleus in monkeys and hypotheses for neuropsychopharmacology. In Meltzer HY (ed), Psychopharmacology: The Third Generation of Progress. New York, Raven Press, pp 967-975

Schatzberg AF, Schildkraut JJ (1995): Recent studies on norepinephrine systems in mood disorders. In Bloom FE, Kupfer DJ (eds), Psychopharmacology: The Fourth Generation of Progress. New York, Raven Press, pp 911-920

Schildkraut JJ (1965): The catecholamine hypothesis of affective disorders: A review of supporting evidence. Am J Psychiat 122:509-522

Schildkraut JJ (1978): Current status of the catecholamine hypothesis of affective disorders. In Lipton MA, DiMascio A, Killam KF (eds), Psychopharmacology: A Generation of Progress. New York, Raven Press, pp 1223-1234

Sheehan BD, Tharyan P, McTavish SFB, Campling GM, Cowen PJ (1996): The use of dietary manipulation to deplete plasma tyrosine and phenylalanine in healthy subjects. J Psychopharmacol 10:231-234

Siever LJ (1987): Role of noradrenergic mechanisms in the etiology of the affective disorders. In Meltzer HY (ed), Psychopharmacology: The Third Generation of Progress. New York, Raven Press, pp 493-504

Sjoerdsma A, Engelman K, Spector S, Udenfriend S (1965): Inhibition of catecholamine synthesis in man with alpha-methyl-tyrosine, an inhibitor of tyrosine hydroxylase. Lancet ii:1092-1094

Sloley BD, Kah O, Trudeau VL, Dulka JG, Peter RE (1992): Amino acid neurotransmitters and dopamine in brain and pituitary of the goldfish: Involvement in the regulation of gonadotrophin secretion. J Neurochem 58:22452262

Smith SE, Pihl RO, Young SN, Ervin FR (1987): A test of possible cognitive and environmental influences on the mood lowering effect of tryptophan depletion in normal males. Psychopharmacology 91:451-457

Spitzer RL (1987): Structured Clinical Interview for DSMIIIR. New York, Biometrics Research Department, New York State Psychiatric Institute

Stancampiano R, Melis F, Sarais L, Cocco S, Cugusi C, Fadda F (1997): Acute administration of a tryptophan-free amino acid mixture decreases 5-HT release in rat hippocampus in vivo. Am J Physiol 272:R991-R994

Stewart J (1995): How does incentive motivational theory apply to sexual behavior? In Bancroft J (ed), The Pharmacology of Sexual Function. Amsterdam, Elsevier Science, pp 3-11

Tam SY, Elsworth JD, Bradberry CW, Roth RH (1990): Mesocortical dopamine neurons: High basal firing frequency predicts tyrosine dependence of dopamine synthesis. J Neural Transm 81:97-110

Tam SY, Roth RH (1997): Mesoprefrontal dopaminergic neurons: Can tyrosine availability influence their functions? Biochem Pharmacol 53:441-453

Trestman RL, Coccaro EF, Bernstein D, Lawrence T, Gabriel SM, Horvath TB, Siever LJ (1991): Cortisol responses to mental arithmetic in acute and remitted depression. Biol Psychiat 29:1051-1054

Wilkins K (1990): Eosinophilia-myalgia syndrome. Can Med Assoc J 142:1265-1266

Willner P (1995): Dopaminergic mechanisms in depression and mania. In Bloom FE, Kupfer DJ (eds), Psychopharmacology: The Fourth Generation of Progress. New York, Raven Press, pp 921-931

Wise RA (1996): Addictive drugs and brain stimulation reward. Ann Rev Neurosci 19:319-340

Wolf ME, Galloway MP, Roth RH (1986): Regulation of dopamine synthesis in the medial prefrontal cortex: Studies in brain slices. J Pharmacol Exp Ther 236:699-707

Wong JT, Baker GB, Coutts RT (1990): A rapid, sensitive assay for gamma-aminobutyric acid in brain using electron-capture gas chromatography. Res Commun Chem Pathol Pharmacol 70:115-124

Yocca FD (1990): Neurochemistry and neurophysiology of buspirone and gepirone: Interactions at presynaptic and postsynaptic 5-HT1A receptors. J Clin Psychopharmacol 10:6S-12S

Young SN, Smith SE, Pihl RO, Ervin FR (1985): Tryptophan depletion causes a rapid lowering of mood in normal males. Psychopharmacology 87:173-177 